\title{
Beta Combination Graphs
}

\author{
T. Tharmaraj \\ Department of Mathematics, Udaya School of \\ Engineering, Vellamodi, Tamil Nadu
}

\author{
P.B.Sarasija \\ Department of Mathematics, Noorul Islam \\ University, \\ Kumaracoil,Tamil Nadu
}

\begin{abstract}
Let $G(V, E)$ be a graph with $p$ vertices and $q$ edges.A graph $\mathrm{G}(\mathrm{p}, \mathrm{q})$ is said to be a Beta combination graph if there exist a bijection $\mathrm{f:} V(\mathrm{G}) \rightarrow\{1,2 \ldots, \mathrm{p}\}$ such that the induced function $B_{f}: E(G) \rightarrow N, N$ is a natural number, given by $B_{f}(u v)=\frac{[f(u)+f(v)] !}{f(u) ! f(v) !}$, every edges uv $\in G$ and are all distinct and the function $\mathrm{f}$ is called the Beta combination labeling.In this paper, we proved the Petersen graph , Complete graph $K_{n}(n \leq 8)$, Ladder $L_{n}(n \geq 2)$, fan $f_{n}(n \geq 2)$, wheel $W_{n}(n \geq 3)$, path $P_{n}$, cycle $C_{n}(n \geq 3)$, friendship graph $F_{n}$ $(n \geq 1)$, complete bipartite graph $K_{n, n}(n \geq 2)$, Tree $T_{n}$, triangle snake, $n$-bistar graph $B_{n, n}$ and Star graph $K_{1, n}(n>1)$ are the Beta combination graphs.Also we proved Complete graph $\mathrm{K}_{\mathrm{n}}$ $(n>8)$ is not a Beta combination graph.
\end{abstract}

\section{General Terms}

Mathematical subject classification(2010) 05 C78.

\section{Keywords}

Beta combination graph and Beta combination labeling.

\section{INTRODUCTION}

The research in graph enumeration and graph labeling started way back in 1857 by Arthur Cayley.Graph labeling and enumeration finds the application in chemical graph theory, social networking and computer networking and channel assignment problem.Abundant literature exists as of today concerning the structure of graphs admitting a variety of functions assigning real numbers to their elements so that certain given conditions are satisfied.

Throughout this paper, by a graph we mean a finite, undirected, simple graph. The vertex set and the edge set of a graph $\mathrm{G}$ are denoted by $\mathrm{V}(\mathrm{G})$ and $\mathrm{E}(\mathrm{G})$ respectively. Let $\mathrm{G}(\mathrm{p}, \mathrm{q})$ be a graph with $\mathrm{p}=|\mathrm{V}(\mathrm{G})|$ vertices and $\mathrm{q}=|\mathrm{E}(\mathrm{G})|$ edges. A detailed survey of graph labeling can be found in [4].Combinations play a major role in combinatorial problems. The new labeling introduced in this paper is a logical-mathematical attempt. We used the following definitions in the subsequent sections.

\section{Definition 1.1}

A graph $G(p, q)$ is said to be a Beta combination graph if there exist a bijection $\mathrm{f:} V(\mathrm{G}) \rightarrow\{1,2 \ldots ., \mathrm{p}\}$ such that the induced function $\mathrm{B}_{\mathrm{f}}: \mathrm{E}(\mathrm{G}) \rightarrow \mathrm{N}, \mathrm{N}$ is a natural number, given by $B_{f}(u v)=\frac{[f(u)+f(v)] !}{f(u) ! f(v) !}$, every edges uv $\in G$ and are all distinct and the function $\mathrm{f}$ is called the Beta combination labeling.

\section{Definition 1.2.[6]}

The Ladder $L_{n}(n \geq 2)$ is the product graph $P_{2} \times P_{n}$ and contains $2 n$ nodes and $3 n-2$ edges.

\section{Definition 1.3.[6]}

The Fan $f_{n}(n \geq 2)$ is obtained by joining all nodes of $P_{n}$ to a further node called the center and contains $n+1$ nodes and $2 n$ 1 edges.

\section{Definition 1.4.[6]}

The $\mathrm{n}$-bistar graph $\mathrm{B}_{\mathrm{n}, \mathrm{n}}$ is the graph obtained from two copies of $K_{1, n}$ by joining the vertices of maximum degree by an edge.

\section{Definition 1.5 .[6]}

The wheel $W_{n}(n \geq 3)$ is obtained by joining all nodes of cycle $C_{n}$ to a further node called the center, and contains $(n+1)$ nodes and $2 n$ edges.

\section{Definition 1.6.[6]}

The friendship graph $F_{n}(n \geq 1)$ consists of $n$ triangles with a common vertex.

\section{Definition 1.7.[6]}

A triangular snake is obtained from a path $\mathrm{v}_{1}, \mathrm{v}_{2}, \ldots, \mathrm{v}_{\mathrm{n}}$ by joining $\mathrm{v}_{\mathrm{i}}$ and $\mathrm{v}_{\mathrm{i}+1}$ to a new vertex $\mathrm{w}_{\mathrm{i}}$ for $\mathrm{i}=1,2, \ldots, \mathrm{n}-1$.

In this paper, we proved the Petersen graph , Complete graph $K_{n}(n \leq 8)$, Ladder $L_{n}(n \geq 2)$, fan $f_{n}(n \geq 2)$, wheel $W_{n}(n \geq 3)$, path $P_{n}$, cycle $C_{n}(n \geq 3)$ friendship graph $F_{n}(n \geq 1)$, complete bipartite graph $K_{n, n}(n \geq 2)$, Tree $T_{n}$, triangle snake, $n$-bistar graph $B_{n, n}$ and Star graph $K_{1, n}(n>1)$ are the Beta combination graphs.Also we proved Complete graph $K_{n}(n>8)$ is not a Beta combination graph.

\section{MAIN RESULTS}




\section{Theorem 2.1}

The Petersen graph is a Beta combination graph.

\section{Proof:}

Let $G$ be the Petersen graph with 10 vertices $u_{1}, u_{2}$, $\ldots \mathrm{u}_{5}, \mathrm{v}_{1}, \mathrm{v}_{2}, \ldots . \mathrm{v}_{5}$. Let $\mathrm{u}_{1}, \mathrm{u}_{2}, \ldots \mathrm{u}_{5}$ be the outer vertices and let $\mathrm{v}_{1}, \mathrm{v}_{2}, \ldots . \mathrm{v}_{5}$ be the vertices of the star.Define $\mathrm{f:} \mathrm{V}(\mathrm{G}) \rightarrow\{1,2$, $\ldots ., 10\}$ by $\mathrm{f}\left(\mathrm{u}_{\mathrm{i}}\right)=2 \mathrm{i}-1$ if $1 \leq \mathrm{i} \leq 5$ and $\mathrm{f}\left(\mathrm{v}_{\mathrm{i}}\right)=2 \mathrm{i}$ if $1 \leq \mathrm{i} \leq 5$. And $f$ induces that $B_{f}: E(G) \rightarrow N$ by

$B_{f}(u v)=\frac{[f(u)+f(v)] !}{f(u) ! f(v) !}$, for every edges uv of $G$ and are all distinct.

\section{Theorem:2.2}

Every $\mathrm{n}$-Bistar $\mathrm{B}_{\mathrm{n}, \mathrm{n}}$ admits a beta combination labeling.

\section{Proof:}

The graph $n$-Bistar $B_{n, n}$ is the graph obtained from two copies of $K_{1, n}$ by joining the vertices of maximum degree by an edge. Let $\mathrm{u}_{1}, \mathrm{u}_{2}, \ldots, \mathrm{u}_{\mathrm{n}}, \mathrm{u}_{\mathrm{n}+1}$ be the vertices of first copy of $\mathrm{K}_{1, \mathrm{n}}$ and let $\mathrm{v}_{1}, \mathrm{v}_{2}, \ldots, \mathrm{v}_{\mathrm{n}}, \mathrm{v}_{\mathrm{n}+1}$ be the vertices of second copy of $\mathrm{K}_{1, \mathrm{n}}$ respectively of $\mathrm{B}_{\mathrm{n}, \mathrm{n}}$. Let $\mathrm{u}_{\mathrm{n}+1}$ and $\mathrm{v}_{\mathrm{n}+1}$ are adjacent in

\section{Example:2.4}

The beta combination labeling of the Petersen graph and $\mathrm{B}_{5,5}$ are shown in the Fig-1 and Fig-2 respectively.

$\mathrm{B}_{\mathrm{n}, \mathrm{n}}$. Define $\mathrm{f}: \mathrm{V}\left(\mathrm{B}_{\mathrm{n}, \mathrm{n}}\right) \rightarrow\{1,2, \ldots, 2 \mathrm{n}+2\}$ by $\mathrm{f}\left(\mathrm{u}_{\mathrm{i}}\right)=2 \mathrm{i}-1$ if $1 \leq \mathrm{i} \leq$ $\mathrm{n}+1$ and $\mathrm{f}\left(\mathrm{v}_{\mathrm{i}}\right)=2 \mathrm{i}$ if $1 \leq \mathrm{i} \leq \mathrm{n}+1$. And $\mathrm{f}$ induces $\mathrm{B}_{\mathrm{f}}: \mathrm{E}\left(\mathrm{B}_{\mathrm{n}, \mathrm{n}}\right) \rightarrow \mathrm{N}$ by $B_{f}(u v)=\frac{[f(u)+f(v)] !}{f(u) ! f(v) !}$, for every edges uv of $B_{n, n}$ and are all distinct.

\section{Theorem:2.3}

All Ladders $\mathrm{L}_{\mathrm{n}}(\mathrm{n} \geq 2)$ are the Beta combination graph.

\section{Proof:}

Let the Ladder $L_{n}$ be the graph with $2 n$ vertices $u_{1}$, $u_{2}$ $\ldots, \mathrm{u}_{\mathrm{n}}, \mathrm{u}_{\mathrm{n}+1}, \ldots, \mathrm{u}_{2 \mathrm{n}}$. Let $\mathrm{u}_{\mathrm{i}}$ is adjacent to $\mathrm{u}_{\mathrm{i}+1}$ if $1 \leq \mathrm{i} \leq 2 \mathrm{n}-1$ and $\mathrm{u}_{\mathrm{i}}$ is adjacent to $\mathrm{u}_{2 \mathrm{n}+1-\mathrm{i}}$ if $1 \leq \mathrm{i} \leq \mathrm{n}-1$. Let $\mathrm{e}_{1}, \mathrm{e}_{2}, \ldots, \mathrm{e}_{3 \mathrm{n}-2}$ be the $3 n-2$ edges of the ladder $L_{n}$ such that $e_{j}=u_{j} u_{j+1}$ if $1 \leq i \leq 2 n-1$ and $e_{2 n-1+j}=u_{j} u_{2 n+1-j}$ if $1 \leq j \leq n-1$.

Define $\mathrm{f}: \mathrm{V}\left(\mathrm{L}_{\mathrm{n}}\right) \rightarrow\{1,2, \ldots, 2 \mathrm{n}\}$ by $\mathrm{f}\left(\mathrm{u}_{\mathrm{i}}\right)=2 \mathrm{i}-1$ if $1 \leq \mathrm{i} \leq \mathrm{n}$ and $\mathrm{f}\left(\mathrm{u}_{2 \mathrm{n}+1-\mathrm{i}}\right)=2 \mathrm{i}$ if $1 \leq \mathrm{i} \leq \mathrm{n}$. And $\mathrm{f}$ induces that $\mathrm{B}_{\mathrm{f}}: \mathrm{E}\left(\mathrm{L}_{\mathrm{n}}\right) \rightarrow \mathrm{N}$ by

$B_{f}(u v)=\frac{[f(u)+f(v)] !}{f(u) ! f(v) !}$, for every edges uv of $L_{n}$ and are all distinct.
Fig-1

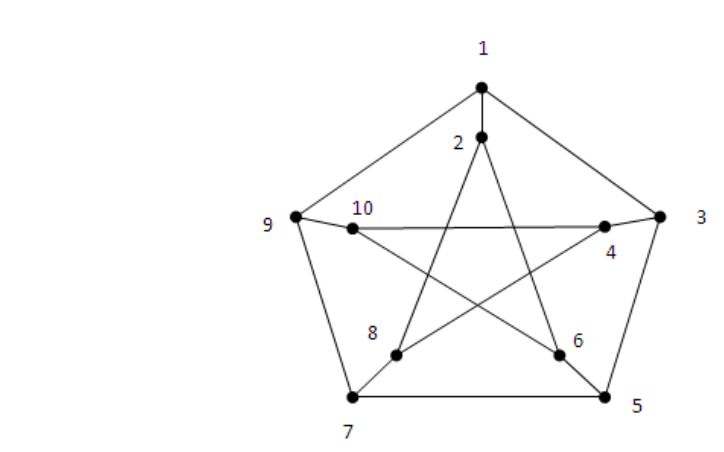

\section{Theorem 2.5}

Every wheel $W_{n}(n \geq 3)$ admits a beta combination labeling.

\section{Proof:}

Let $\mathrm{W}_{\mathrm{n}}=\mathrm{C}_{\mathrm{n}}+\mathrm{K}_{1}$. Let $\mathrm{u}_{1}, \mathrm{u}_{2}, \ldots, \mathrm{u}_{\mathrm{n}}$ be the vertices of $\mathrm{C}_{\mathrm{n}}$ and $u_{n+1}$ be the vertex of $K_{1}$.

Case (i) $\left[n \neq(2 m+1) C_{m}-2, m \geq 2\right.$ and $\left.n \neq(2 m+1) C_{m}-1, m \geq 2\right]$

Define $\mathrm{f}: \mathrm{V}\left(\mathrm{W}_{\mathrm{n}}\right) \rightarrow\{1,2, \ldots, \mathrm{n}+1\}$ by $\mathrm{f}\left(\mathrm{u}_{\mathrm{i}}\right)=\mathrm{i}$ if $\mathrm{l} \leq \mathrm{i} \leq \mathrm{n}+1$.

Case(ii) $\left[n=(2 m+1) C_{m}-2, m \geq 2\right]$

Define $\mathrm{f}: \mathrm{V}\left(\mathrm{W}_{\mathrm{n}}\right) \rightarrow\{1,2, \ldots, \mathrm{n}+1\}$ by $\mathrm{f}\left(\mathrm{u}_{\mathrm{m}-1}\right)=\mathrm{m}, \mathrm{f}\left(\mathrm{u}_{\mathrm{m}}\right)=\mathrm{m}-1$ and $\mathrm{f}\left(\mathrm{u}_{\mathrm{i}}\right)=\mathrm{i}$ if $1 \leq \mathrm{i} \leq \mathrm{n}+1, \mathrm{i} \neq \mathrm{m}-1, \mathrm{~m}$.

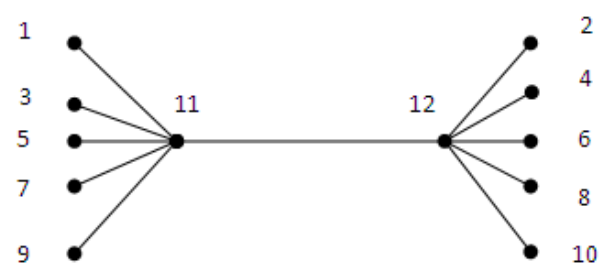

Fig-2

Case(iii) $\left[\mathrm{n}=(2 \mathrm{~m}+1) \mathrm{C}_{\mathrm{m}}-1, \mathrm{~m} \geq 2\right]$

Define $\mathrm{f}: \mathrm{V}\left(\mathrm{W}_{\mathrm{n}}\right) \rightarrow\{1,2, \ldots, \mathrm{n}+1\}$ by $\mathrm{f}\left(\mathrm{u}_{1}\right)=2, \mathrm{f}\left(\mathrm{u}_{2}\right)=1$ and $\mathrm{f}\left(\mathrm{u}_{\mathrm{i}}\right)=\mathrm{i}$ if $3 \leq \mathrm{i} \leq \mathrm{n}+1$.

In all above cases $\mathrm{f}$ induces that $\mathrm{B}_{\mathrm{f}}: \mathrm{E}\left(\mathrm{W}_{\mathrm{n}}\right) \rightarrow \mathrm{N}$ by

$B_{f}(u v)=\frac{[f(u)+f(v)] !}{f(u) ! f(v) !}$, for every edges uv of $W_{n}$ and are all distinct.

Theorem:2.6

Every Complete bipartite graph $\mathrm{K}_{\mathrm{n}, \mathrm{n}}$ admits beta combination labeling. 


\section{Proof:}

Let $\mathrm{u}_{1}, \mathrm{u}_{2}, \ldots, \mathrm{u}_{\mathrm{n}}, \mathrm{v}_{1}, \mathrm{v}_{2}, \ldots, \mathrm{v}_{\mathrm{n}}$ be the vertices of $\mathrm{K}_{\mathrm{n}, \mathrm{n}}$. Let $K_{n, n}=G_{1}+G_{2}$ such that $u_{1}, u_{2}, \ldots, u_{n}$ be the vertices of $G_{1}$ and $\mathrm{v}_{1}, \mathrm{~V}_{2}, \ldots, \mathrm{v}_{\mathrm{n}}$ be the vertices of $\mathrm{G}_{2}$. Define $\mathrm{f:V}\left(\mathrm{K}_{\mathrm{n}, \mathrm{n}}\right) \rightarrow$ $\left\{1,2, \ldots, 2 \mathrm{n}\right.$ by $\mathrm{f}\left(\mathrm{u}_{\mathrm{i}}\right)=2 \mathrm{i}-1$ if $1 \leq \mathrm{i} \leq \mathrm{n}$ and $\mathrm{f}\left(\mathrm{v}_{\mathrm{i}}\right)=2 \mathrm{i}$ if $1 \leq \mathrm{i} \leq \mathrm{n}$. And finduces that $B_{f}: E\left(K_{n, n}\right) \rightarrow N$ by $B_{f}(u v)=\frac{[f(u)+f(v)] !}{f(u) ! f(v) !}$, for every edges $u v$ of $K_{n, n}$ and are all distinct.

\section{Theorem 2.7}

Every star $K_{1, n}(n \geq 2)$ is a beta combination graph.

\section{Proof:}

Let $\mathrm{u}_{1}, \mathrm{u}_{2}, \ldots \ldots, \mathrm{u}_{\mathrm{n}}, \mathrm{u}_{\mathrm{n}+1}$ be the vertices of $\mathrm{K}_{1, \mathrm{n}}$. Then $\mathrm{K}_{1, \mathrm{n}}=\mathrm{G}_{1}+\mathrm{G}_{2}$ such that $\mathrm{u}_{1}$ be the vertex of $\mathrm{G}_{1}$ and $\mathrm{u}_{2}, \ldots \ldots, \mathrm{u}_{\mathrm{n}}, \mathrm{u}_{\mathrm{n}+1}$ be the vertices of $\mathrm{G}_{2}$. Define $\mathrm{f}: \mathrm{V}\left(\mathrm{K}_{1, \mathrm{n}}\right)$ $\rightarrow\{1,2, \ldots, \mathrm{n}+1\}$ by $\mathrm{f}\left(\mathrm{u}_{\mathrm{i}}\right)=\mathrm{i}$ if $1 \leq \mathrm{i} \leq \mathrm{n}+1$. And $\mathrm{f}$ induces that $B_{f}: E\left(K_{1, n}\right) \rightarrow N$ by $B_{f}(u v)=\frac{[f(u)+f(v)] !}{f(u) ! f(v) !}$, for every edges $\mathrm{uv}$ of $\mathrm{K}_{1, \mathrm{n}}$ and are all distinct.

\section{Example 2.8}

The beta combination labeling of $\mathrm{F}_{4}$ and a triangle snake are shown in the Fig-3 and Fig-4 respectively.

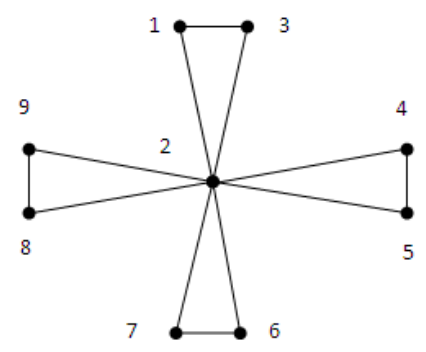

Fig-3

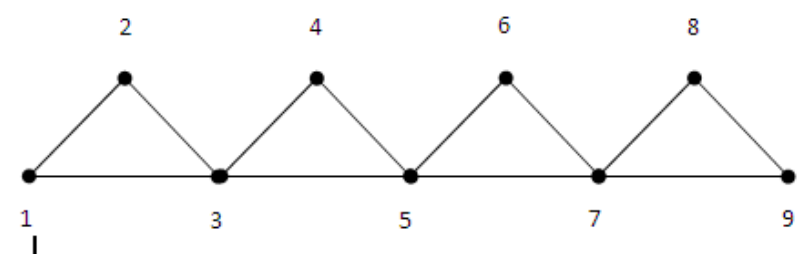

Fig-4

\section{Theorem:2.9}

Every triangle snake is a beta combination graph.

\section{Proof:}

Let $G$ be a triangle snake with vertices $\left\{u_{1}, u_{2}\right.$, $\left.\ldots, \mathrm{u}_{n}, \mathrm{v}_{1}, \mathrm{v}_{2}, \ldots, \mathrm{v}_{\mathrm{n}}, \mathrm{v}_{\mathrm{n}+1}\right\}$. Then $\left\{\mathrm{u}_{\mathrm{i}} \mathrm{v}_{\mathrm{i}}, \mathrm{u}_{\mathrm{i}} \mathrm{v}_{\mathrm{i}+1}, \mathrm{v}_{\mathrm{i}} \mathrm{v}_{\mathrm{i}+1} / 1 \leq \mathrm{i} \leq \mathrm{n}\right\}$ be the edges of G. Define $\mathrm{f:V}(\mathrm{G}) \rightarrow\{1,2, \ldots, 2 \mathrm{n}+1\}$ by $\mathrm{f}\left(\mathrm{u}_{\mathrm{i}}\right)=2 \mathrm{i}$ if $1 \leq \mathrm{i} \leq \mathrm{n}$ and $\mathrm{f}\left(\mathrm{v}_{\mathrm{i}}\right)=2 \mathrm{i}-1$ if $1 \leq \mathrm{i} \leq \mathrm{n}+1$. And $\mathrm{f}$ induces

that $B_{\mathrm{f}}: E(G) \rightarrow N$ by $B_{f}(u v)=\frac{[f(u)+f(v)] !}{f(u) ! f(v) !}$, for every edges uv of $\mathrm{G}$ and are all distinct.

\section{Theorem:2.10}

Friendship graph $F_{n}(n \geq 1)$ is a beta combination graph.

Proof:

Let $\mathrm{u}_{1}, \mathrm{u}_{2}, \ldots \ldots, \mathrm{u}_{2 \mathrm{n}+1}$ be the vertices of $F_{n}$. Also $F_{n}$ has $n$ number of triangles with common vertex $u_{2 n+1}$. Then $F_{n}$ has $n$ number of pairs such as $\left(\mathrm{u}_{1}, \mathrm{u}_{2}\right),\left(\mathrm{u}_{3}, \mathrm{u}_{4}\right), \ldots \ldots,\left(\mathrm{u}_{2 \mathrm{n}-1}, \mathrm{u}_{2 \mathrm{n}}\right)$. Let $\mathrm{e}_{1}, \mathrm{e}_{2}, \ldots, \mathrm{e}_{2 n}$ be the $3 \mathrm{n}$ number of edges of $\mathrm{F}_{\mathrm{n}}$ such that $\mathrm{e}_{\mathrm{i}}=\mathrm{u}_{\mathrm{i}} \mathrm{u}_{\mathrm{i}+1}, \mathrm{i}=2 \mathrm{~m}-1$ if $1 \leq \mathrm{m} \leq \mathrm{n}$ and $\mathrm{e}_{\mathrm{n}+\mathrm{i}}=\mathrm{u}_{\mathrm{i}} \mathrm{u}_{2 \mathrm{n}+1}$ if $1 \leq \mathrm{i} \leq 2 \mathrm{n}$.

[see fig 3].Define $\mathrm{f}: \mathrm{V}\left(\mathrm{F}_{\mathrm{n}}\right) \rightarrow\{1,2, \ldots \ldots, 2 \mathrm{n}+1\}$ by $\mathrm{f}\left(\mathrm{u}_{1}\right)=1$, $\mathrm{f}\left(\mathrm{u}_{\mathrm{i}}\right)=\mathrm{i}+1$ if $2 \leq \mathrm{i} \leq 2 \mathrm{n}$ and $\mathrm{f}\left(\mathrm{u}_{2 n+1}\right)=2$.And $\mathrm{f}$ induces

$B_{f}: E\left(F_{n}\right) \rightarrow N$ by $B_{f}(u v)=\frac{[f(u)+f(v)] !}{f(u) ! f(v) !}$, for every edges uv of $F_{n}$ are all distinct.

\section{Theorem :2.11}

Every path $\mathrm{P}_{\mathrm{n}}$ is a Beta Combination graph.

Proof:

Let $\mathrm{u}_{1}, \mathrm{u}_{2}, \ldots \ldots \mathrm{u}_{\mathrm{n}}$ be the vertices of path $\mathrm{P}_{\mathrm{n}}$ and let $\mathrm{e}_{1}, \mathrm{e}_{2}, \ldots \ldots, \mathrm{e}_{\mathrm{n}-1}$ be the $\mathrm{n}-1$ edges of $\mathrm{P}_{\mathrm{n}}$ such that $\mathrm{e}_{\mathrm{i}}=\mathrm{u}_{\mathrm{i}} \mathrm{u}_{\mathrm{i}+1}$ if $1 \leq \mathrm{i} \leq \mathrm{n}-1$. A bijection $\mathrm{f}: \mathrm{V}\left(\mathrm{P}_{\mathrm{n}}\right) \rightarrow\{1,2,3, \ldots \ldots, \mathrm{n}\}$ is defined by $\mathrm{f}\left(\mathrm{u}_{\mathrm{i}}\right)$ $=\mathrm{i}$, if $1 \leq \mathrm{i} \leq \mathrm{n}$. And $\mathrm{f}$ induces that $\mathrm{B}_{\mathrm{f}}: \mathrm{E}\left(\mathrm{P}_{\mathrm{n}}\right) \rightarrow \mathrm{N}$ by $\mathrm{B}_{\mathrm{f}}(\mathrm{uv})=$ $\frac{[\mathrm{f}(\mathrm{u})+\mathrm{f}(\mathrm{v})] !}{\mathrm{f}(\mathrm{u}) ! \mathrm{f}(\mathrm{v}) !}$ for every edges uv in $\mathrm{P}_{\mathrm{n}}$ and are all distinct.

\section{Theorem :2.12}

Every Cycle $C_{n}(n \geq 3)$ is a Beta Combination graph.

Proof:

Let $\mathrm{u}_{1}, \mathrm{u}_{2}, \ldots \ldots \mathrm{u}_{\mathrm{n}}$ be the vertices of $\mathrm{C}_{\mathrm{n}}$ such that $\mathrm{u}_{1}$ is adjacent to $u_{n}$ and $u_{i}$ is adjacent to $u_{i+1}$ if $1 \leq i \leq n-1$.Then $e_{i}=u_{i} u_{i+1}$ if $1 \leq i \leq n-1$ and $e_{n}=u_{1} u_{n}$ be the $n$ edges of $C_{n}$.

.Case $(i)\left[n \neq(2 m+1) C_{m}-1, m \geq 2\right]$

Define a bijection $\mathrm{f}: \mathrm{V}\left(\mathrm{C}_{\mathrm{n}}\right) \rightarrow\{1,2,3, \ldots ., \mathrm{n}\}$ is defined by $\mathrm{f}\left(\mathrm{u}_{\mathrm{i}}\right)=\mathrm{i}$, if $1 \leq \mathrm{i} \leq \mathrm{n}$.

Case(ii) $\left[n=(2 m+1) C_{m}-1, m \geq 2\right]$

Define a bijection $\mathrm{f}: \mathrm{V}\left(\mathrm{C}_{\mathrm{n}}\right) \rightarrow\{1,2,3, \ldots \ldots, \mathrm{n}\}$ is defined by 
$\mathrm{f}\left(\mathrm{u}_{1}\right)=2, \mathrm{f}\left(\mathrm{u}_{2}\right)=1$ and $\mathrm{f}\left(\mathrm{u}_{\mathrm{i}}\right)=\mathrm{i}$ if $3 \leq \mathrm{i} \leq \mathrm{n}$.

In all above cases $f$ induces that $B_{f}: E\left(C_{n}\right) \rightarrow\{1,2,3, \ldots .$.$\} by$

$B_{f}(u v)=\frac{[f(u)+f(v)] !}{f(u) ! f(v) !}$ for every edges uv in $C_{n}$ and are all distinct.

\section{Theorem:2.13}

Every Complete graph $\mathrm{K}_{\mathrm{n}}(\mathrm{n} \leq 8)$ is a Beta Combination graph

\section{Proof:}

Let $\mathrm{u}_{1}, \mathrm{u}_{2}, \ldots \ldots . \mathrm{u}_{\mathrm{n}}$ be the $\mathrm{n}$ vertices of complete graph $\mathrm{K}_{\mathrm{n}}$. Define $\mathrm{f}: \mathrm{V}\left(\mathrm{K}_{\mathrm{n}}\right) \rightarrow\{1,2,3, \ldots \ldots, \mathrm{n}\}$ by $\mathrm{f}\left(\mathrm{u}_{\mathrm{i}}\right)=\mathrm{i}$ if $1 \leq \mathrm{i} \leq \mathrm{n}$. And $\mathrm{f}$ induces that $B_{f}: E\left(K_{n}\right) \rightarrow N$ by $B_{f}(u v)=\frac{[f(u)+f(v)] !}{f(u) ! f(v) !}$, for every edges $u v$ in $\mathrm{K}_{\mathrm{n}}$ and are all distinct.

\section{Theorem 2.14}

Complete graph $K_{n}$ is not a Beta Combination graph for $n>8$.

\section{Proof:}

For $\mathrm{n}>8$, we get $10 \mathrm{C}_{1}=5 \mathrm{C}_{2}=10$. Therefore $\mathrm{K}_{\mathrm{n}}$ does not admit a beta combination labeling as induced edge function is not injective for $\mathrm{n}>8$ [see Fig-5].

\section{Example 2.15}

An example of a non beta combination graph $\mathrm{K}_{9}$ is displayed in Fig-5.

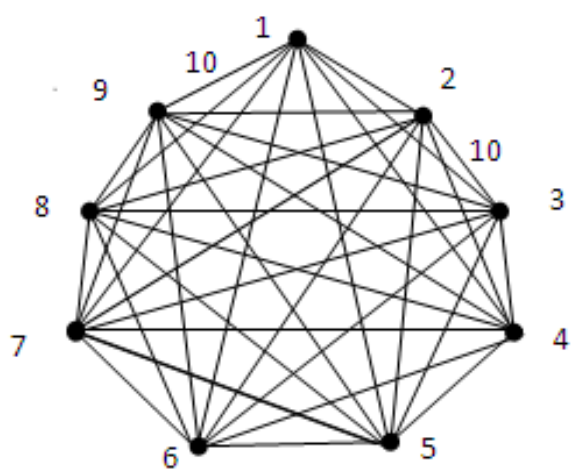

Fig-5

\section{Theorem:2.16}

Every fan graph $f_{n}(n \geq 2)$ is a beta combination graph.

Proof:
Let $u_{1}, u_{2}, \ldots \ldots . . u_{n}, u_{n+1}$ be the $n+1$ vertices of $f_{n}$. Then $\mathrm{f}_{\mathrm{n}}=\mathrm{K}_{1}+\mathrm{P}_{\mathrm{n}}$. Let $\mathrm{K}_{1}=\mathrm{u}_{\mathrm{n}+1}$ and $\mathrm{u}_{\mathrm{n}+1}$ is adjacent to every vertices $\mathrm{u}_{1}, \mathrm{u}_{2}, \ldots \ldots \mathrm{u}_{\mathrm{n}}$ of path $\mathrm{P}_{\mathrm{n}}$.

Case(i) $\left[n \neq(2 m+1) C_{m}-2, m \geq 2\right]$

Define $\mathrm{f}: \mathrm{V}\left(\mathrm{f}_{\mathrm{n}}\right) \rightarrow\{1,2,3, \ldots \ldots, \mathrm{n}+1\}$ by $\mathrm{f}\left(\mathrm{u}_{\mathrm{i}}\right)=\mathrm{i}, 1 \leq \mathrm{i} \leq \mathrm{n}+1$.

Case(ii) $\left[n=(2 m+1) C_{m}-2, m \geq 2\right]$

Define $\mathrm{f}: \mathrm{V}\left(\mathrm{f}_{\mathrm{n}}\right) \rightarrow\{1,2,3, \ldots, \mathrm{n}+1\}$ by $\mathrm{f}\left(\mathrm{u}_{\mathrm{m}-1}\right)=\mathrm{m}, \mathrm{f}\left(\mathrm{u}_{\mathrm{m}}\right)=\mathrm{m}-1$, $\mathrm{f}\left(\mathrm{u}_{\mathrm{i}}\right)=\mathrm{i}$ if $1 \leq \mathrm{i} \leq \mathrm{n}+1$ and $\mathrm{i} \neq \mathrm{m}-1, \mathrm{~m}$.

In all above cases $\mathrm{f}$ induces that $\mathrm{B}_{\mathrm{f}}: \mathrm{E}\left(\mathrm{f}_{\mathrm{n}}\right) \rightarrow \mathrm{N}$ by $B_{f}(u v)=\frac{[f(u)+f(v)] !}{f(u) ! f(v) !}$, for every edges uv in $f_{n}$ and are all distinct.

\section{Theorem 2.17}

Every tree is a beta combination graph

Proof:

Let $\mathrm{u}_{1}$ denote the root vertex of the tree graph and labeling this vertex $u_{1}$ as ' 1 '. If the vertex $u_{1}$ has ' $i$ ' sub trees with rooted vertices as $\mathrm{u}_{2}, \mathrm{u}_{3}, \ldots \mathrm{u}_{\mathrm{i}}$ then labeling each vertex as $2,3,4, \ldots$ i. similarly each of the above vertices has one or more sub trees with labeling $i+1, i+2, \ldots$ continuing this process we get beta combination tree graph.[see Fig-6].

\section{Example 2.18}

The beta combination labeling of a tree $T_{6}$ is shown in the Fig-6 .

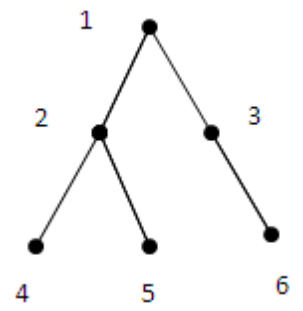

Fig-6

\section{ACKNOWLEDGMENTS}

Our thanks to the experts who have contributed towards development of the Paper.

\section{CONCLUSION}

We have planned to find more beta combination graphs

\section{REFERENCES:}

[1] B.D.Acharya and S.M.Hegde,Arithmetic graphs,J.Graph Theory,14(3)(1990),275-299. 
[2] L.Beineke and S.M.Hegde,Stronly multiplicative graphs,Discuss.Math.Graph Theory, 21(2001),63-75.

[3] D.M.Burton,Elementary Number Theory,Second Edition,Wm.C.Brown company Publishers, 1980.

[4] J.A.Gallian,A dynamic survey of graph labeling, The Electronic journal of combinatorics,5(2002),\# DS6,1-144.
[5] S.M.Hegde and Sudhakar Shetty,Combinatorial Labelings of Graphs,Applied Mathematics E-Notes, 6(2006),251-258.

[6] F.Harary, Graph Theory,Addison-Wesley, Reading,Massachusetts, 1972 